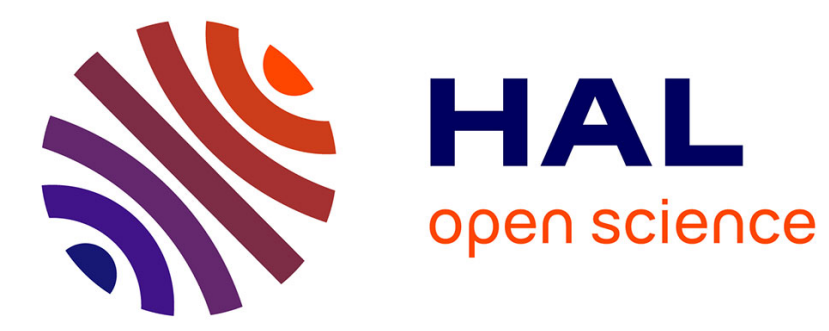

\title{
Deposition of Boron Nitride Films from BB'B"-Trichloroborazine
}

\author{
R. Stolle, G. Wahl
}

\section{To cite this version:}

R. Stolle, G. Wahl. Deposition of Boron Nitride Films from BB'B"-Trichloroborazine. Journal de Physique IV Proceedings, 1995, 05 (C5), pp.C5-761-C5-768. 10.1051/jphyscol:1995590 . jpa00253952

\section{HAL Id: jpa-00253952 https://hal.science/jpa-00253952}

Submitted on 1 Jan 1995

HAL is a multi-disciplinary open access archive for the deposit and dissemination of scientific research documents, whether they are published or not. The documents may come from teaching and research institutions in France or abroad, or from public or private research centers.
L'archive ouverte pluridisciplinaire HAL, est destinée au dépôt et à la diffusion de documents scientifiques de niveau recherche, publiés ou non, émanant des établissements d'enseignement et de recherche français ou étrangers, des laboratoires publics ou privés. 
JUURNAL DE PHYSIQUE IV

Colloque C5, supplément au Journal de Physique II, Volume 5, juin 1995

\title{
Deposition of Boron Nitride Films from BB'B"-Trichloroborazine
}

\author{
R. Stolle and G. Wahl \\ Institut für Oberflächentechnik und Plasmatechnische Werkstoffentwicklung, Technische Universität \\ Braunschweig, Bienroder Weg 53, 38108 Braunschweig, Germany
}

\begin{abstract}
The Chemical Vapor Deposition of boron nitride from BB'B"-Trichloroborazine was investigated in a microbalance equipment with a hot wall reactor. It was possible to monitor the evaporating and depositing masses simultaneously, so that the kinetics of the CVD-process could be measured in detail. The evaporation rate was studied in the temperature range between 285 and $330 \mathrm{~K}$. The activation energy of the evaporation was determined to be $65 \pm 2 \mathrm{~kJ} / \mathrm{mole}$. The deposition process was investigated at temperatures between 973 and $1233 \mathrm{~K}$ in an argon atmosphere at total pressures between 250 and $2000 \mathrm{~Pa}$. The deposition of boron nitride on silicon could be described by a Langmuir reaction type. A gas phase decomposition of BB'B"-Trichloroborazine was observed, so that the concentration at the substrate was dependent on the residence time of the precursor in the hot zone of the reactor. The deposited layers were colorless and amorphous and had the correct $1 / 1$ stoichiometry between boron and nitrogen (WDX-Analysis). The layers contained less than $1 \%$ of chlorine. SiC-Tyranno-fiber fabrics were coated homogeneously with BN-layers of 200-300 nm thickness. A tensile strength decrease of approximately $15 \%$ was observed for the coated fibers. Oxidation experiments showed that the layers were oxidized at temperatures above $873 \mathrm{~K}$ in an $\mathrm{Ar} / \mathrm{O}_{2}$-atmosphere leading to a brittle behavior of the fibers.
\end{abstract}

\section{INTRODUCTION}

Boron nitride thin films are an interesting material for ceramic matrix composites (CMC's) as an interlayer between fibers and matrix. Boron nitride reduces the adhesion between fibers and matrix, preventing a brittle behavior of the composite. Presently in most cases carbon layers are used for this application but they oxidize in air at temperatures above approximately $750 \mathrm{~K}$. Since boron nitride is more oxidation resistant than carbon, the boron nitride deposition was investigated. In most cases boron nitride is deposited from $\mathrm{BCl}_{3} / \mathrm{NH}_{3}$ or $\mathrm{BF}_{3} / \mathrm{NH}_{3}$ with typical deposition temperatures between 1300 and $1600 \mathrm{~K}[1,2]$. Ammonia has to be supplied in excess in order to obtain stoichiometric BN-layers. Investigations of Pysher et al. [3] have shown, that SiC-Tyranno-fibers, which were used for the composites in the case investigated, are partly degraded under these deposition conditions. For that reason only precursors were used, which decompose at lower deposition temperatures. The precursors investigated were NN'N"-Trimethylborazine, the Borane-Ammonia-complex, the Borane-Triethylaminecomplex and BB'B"-Trichloroborazine. Stoichiometric boron nitride layers were only obtained with BB'B"-Trichloroborazine, so that this precursor was selected for further investigations. The evaporation and deposition kinetics of all precursors were investigated in a hot wall reactor with microbalances. This was necessary to find deposition conditions for homogeneous infiltration of the Tyranno-fiber fabrics.

\section{EXPERIMENTAL SETUP}

The kinetic investigations were performed in a hot wall CVD-system with microbalances. The crucible for the precursor and the substrate were connected with the balances outside the vacuum system by a magnetic suspension coupling. This system allowed to obtain detailed information about the influence of gas phase composition, pressure, temperature and gas flow on the evaporation and deposition processes. Therefore kinetic rate laws of CVD processes could be determined in a very short time with high 
accuracy. Besides, the system permitted to monitor the influence of the substrate surface. So it was possible, to find out, if the deposition rate changed during the deposition process. Such effects can hardly be monitored in a conventional CVD-system, because in such a case only integral data are obtained. Schemes of the CVD-system and the reactor setup are shown in Fig. 1a and $1 \mathrm{~b}$.

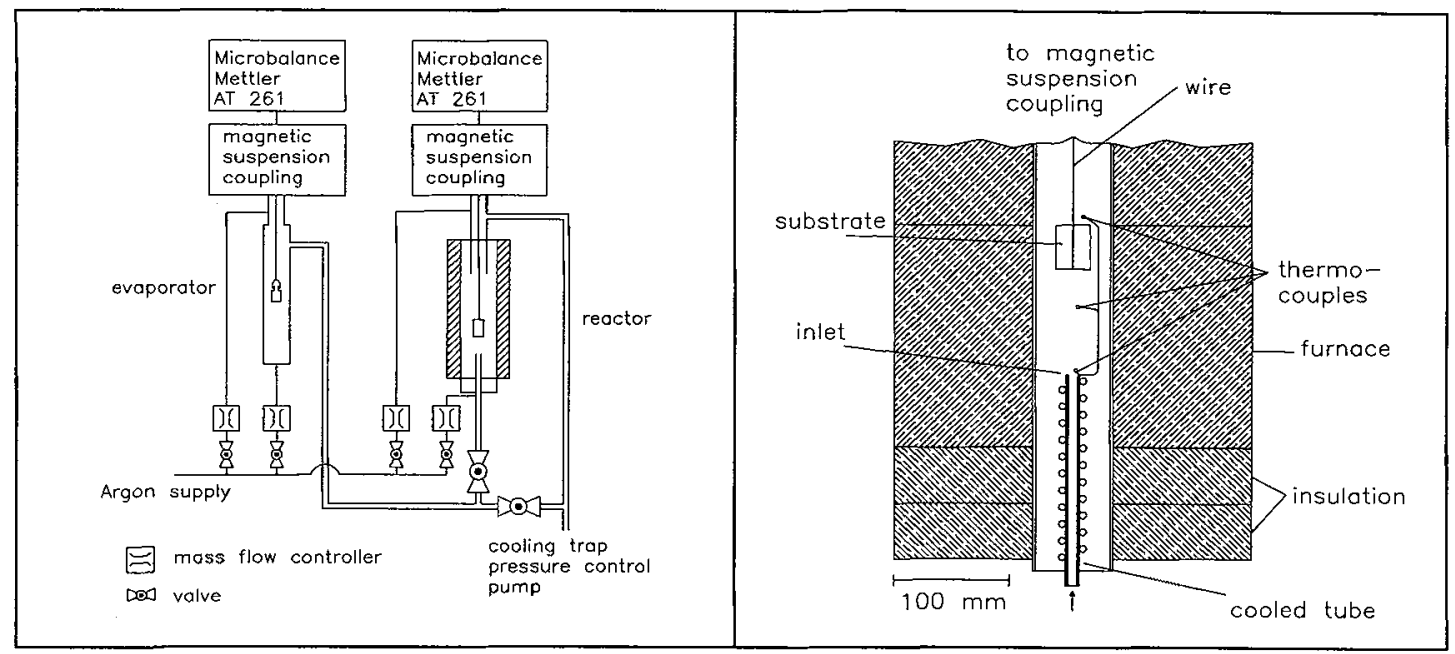

Fig. 1a. Scheme of the microbalance CVD-equipment

Fig. ib. Scheme of the hot wall CVD-reactor

The magnetic suspension coupling (Rubotherm, Bochum, Germany) consisted of an electromagnet and a permanent magnet, which were separated by the coupling housing. The electromagnet was attached to the underfloor weighing hook of the microbalance outside the vacuum system. Inside the coupling housing was a permanent magnet, which was linked to the sample. To achieve a freely suspended state of the permanent magnet, its absolute position was detected by a position sensor and was controlled in a direct and fast loop (PID controller). The magnetic suspension coupling facilitated to transfer the $10 \mu \mathrm{g}$ resolution of the microbalances (Mettler AT 261) to the CVD-system. The maximum load was limited to approximately $40 \mathrm{~g}$. The interior of the coupling housing was purged with argon to prevent contamination of the permanent magnet.

The evaporator consisted of a stainless steel tube (internal diameter $d=60 \mathrm{~mm}$ ). The temperature was measured with a $\mathrm{NiCr} / \mathrm{Ni}$ thermocouple located in a distance of approximately $10 \mathrm{~mm}$ lateral of the crucible. The temperature readout was taken to control the flexible tapes used for heating the evaporator. The evaporation crucible was located in a distance of approximately $600 \mathrm{~mm}$ from the inlet of the carrier gas into the evaporator to guarantee that the system was isothermal.

The reactor tube was made of quartz (internal diameter $d=65 \mathrm{~mm}$, length $l=1000 \mathrm{~mm}$ ). It was heated by an electric furnace with three zones of $200 \mathrm{~mm}$ heated length each. The inlet of the reactor consisted of a cooled tube with an internal diameter of $8 \mathrm{~mm}$, which reached $65 \mathrm{~mm}$ into the lower heating zone. The lower edge of the Si-substrate (length $l=40 \mathrm{~mm}$ ) was positioned approximately $95 \mathrm{~mm}$ above the end of the inlet tube in parallel flow arrangement. The temperatures were measured at the end of the inlet tube, $30 \mathrm{~mm}$ below the substrate and $10 \mathrm{~mm}$ above the substrate in the gas phase with $\mathrm{NiCr} / \mathrm{Ni}$ thermocouples. The temperature readings below and above the substrate were used to control the temperature of the furnace. The inlet tube cooling was applied to keep the gas temperature in the reactor inlet approximately $200 \mathrm{~K}$ below the deposition temperature to prevent precursor loss by decomposition. With this arrangement it was possible to achieve a uniform temperature zone along the substrate leading to a homogeneous coating. The chrome-nickel-wire $(d=0.25 \mathrm{~mm})$ which attached the substrate to the magnetic suspension coupling was purged on its upper end with argon to keep the deposition on the wire low, compared to the deposition on the substrate. The mass deposited on the wire was approximately $5 \%$ of the total mass deposited and was neglected. 
Temperatures, total pressure, gas flows and valves were controlled by computer. So it was possible to conduct long term measurements. All process parameters were read out every minute, the masses were recorded every 30 seconds.

\section{RESULTS AND DISCUSSION}

\subsection{Selection of Precursor}

Due to possible fiber damage an important criterion for the selection of a suitable precursor was a deposition temperature below $1200 \mathrm{~K}$. Carbon free BN-layers of correct stoichiometry should be deposited. For an easy process control only precursors containing boron and nitrogen in the ratio $1 / 1$ in one molecule were studied. The investigated precursors and the experimental conditions are shown in Table 1.

Table 1. Experimental conditions of the deposition experiments

\begin{tabular}{|l|c|c|c|c|r|}
\hline Precursor & $\begin{array}{l}\text { Total pressure } \\
{[\mathrm{Pa}]}\end{array}$ & $\begin{array}{l}\text { Argon flow } \\
{\left[\mathrm{l}_{\mathrm{n}} \mathrm{h}^{-1}\right]}\end{array}$ & $\begin{array}{l}\text { Precursor concen- } \\
\text { tration }\left[\mathrm{mol} \mathrm{m}^{-3}\right]\end{array}$ & $\mathrm{T}_{\text {evap }}[\mathrm{K}]$ & $\mathrm{T}_{\mathrm{dep}}[\mathrm{K}]$ \\
\hline NN'N"-Trimethylborazine & $200-100000$ & $2.5-15$ & $3.3-25 * 10^{-4}$ & $298-400$ & $923-1273$ \\
\hline Borane-Ammonia-complex & 70 & 5 & $2.5-4.6 * 10^{-5}$ & $293-363$ & $623-893$ \\
\hline $\begin{array}{l}\text { Borane-Triethylamine- } \\
\text { complex }\end{array}$ & 200 & $5-10$ & $2.9-7.1 * 10^{-4}$ & $290-326$ & $585-1173$ \\
\hline BB'B"-Trichloroborazine & $250-2000$ & $7.5-15$ & $0.8-8.5 * 10^{-4}$ & $282-343$ & $973-1233$ \\
\hline
\end{tabular}

Only BB'B"-Trichloroborazine fulfilled all requirements mentioned above. The reasons to reject the other precursors investigated are shown in Table 2.

Table 2. Disadvantages of precursors investigated for boron nitride deposition

\begin{tabular}{|l|l|}
\hline Precursor & Disadvantages \\
\hline NN'N"-Trimethylborazine & $\begin{array}{l}\text { Typical layer composition: } \mathrm{BN}_{0.55} \mathrm{C}_{\mathrm{x}}(1133 \mathrm{~K}, 400 \mathrm{~Pa}) \\
80 \% \text { strength decrease for } 0.3 \mu \mathrm{m} \text { thick coated Tyranno-fibers } \\
\left(\mathrm{T}_{\text {dep }}=1123 \mathrm{~K}, \mathrm{p}_{\text {tot }}=200 \mathrm{~Pa}\right)\end{array}$ \\
\hline $\begin{array}{l}\text { Borane-Ammonia- } \\
\text { complex }\end{array}$ & $\begin{array}{l}\text { Typical layer composition: } \mathrm{BN}_{0.3}(773 \mathrm{~K}, 70 \mathrm{~Pa}) \\
\text { Spontaneous decomposition of the precursor at } \mathrm{T}_{\text {evap }}>338 \mathrm{~K} \\
\text { Deposition rates in the range of } 5 \mathrm{~nm} \text { per hour }\end{array}$ \\
\hline $\begin{array}{l}\text { Borane-Triethylamine- } \\
\text { complex }\end{array}$ & $\begin{array}{l}\text { Typical layer composition: } \mathrm{BN}_{0.25} \mathrm{C}_{\mathrm{x}}(1173 \mathrm{~K}, 200 \mathrm{~Pa}) \\
\text { Tyranno-fiber fragmentation by deposition at } 585 \mathrm{~K} \text { and } 200 \mathrm{~Pa}\end{array}$ \\
\hline
\end{tabular}

With BB'B"-Trichloroborazine stoichiometric BN-layers were deposited at temperatures between 973 and $1233 \mathrm{~K}$ according to the reaction $\mathrm{B}_{3} \mathrm{~N}_{3} \mathrm{H}_{3} \mathrm{Cl}_{3} \rightarrow 3 \mathrm{BN}+3 \mathrm{HCl}$. BB'B"-Trichloroborazine was used for boron nitride CVD by Singh [5] and Gebhardt [6], but no detailed kinetic data for the CVD-process under hot wall deposition conditions was available.

\subsection{Preparation of BB'B"-Trichloroborazine}

$\mathrm{BB}^{\prime} \mathrm{B}$ "-Trichloroborazine was prepared according to the method of Brown and Laubengayer [7]. $\mathrm{BCl}_{3}$ was passed through solid $\mathrm{NH}_{4} \mathrm{Cl}$ in a packed bed reactor at temperatures between 433 and $473 \mathrm{~K}$ at atmospheric pressure. BB'B''-Trichloroborazine was condensed, the exhaust gases were absorbed by water. The yield of the reaction was approximately $10 \%$. The product was identified by its melting point of $356-359 \mathrm{~K}$ and its NMR spectra: ${ }^{1} \mathrm{H}-\mathrm{NMR}: \delta=5.29 \mathrm{ppm},{ }^{11} \mathrm{~B}-\mathrm{NMR}: \delta=30.07 \mathrm{ppm}$.

\subsection{Evaporation behavior of $B B^{\prime} B^{\prime \prime}$-Trichloroborazine}

The evaporation behavior of $\mathrm{BB}^{\prime} \mathrm{B}$ "-Trichloroborazine was investigated in the temperature range between 285 and $320 \mathrm{~K}$ at a total pressure of 200,400 and $800 \mathrm{~Pa}$ in the microbalance equipment. A glass vial ( 28 $\mathrm{mm}$ diameter, $40 \mathrm{~mm}$ height, $17 \mathrm{~mm}$ outlet diameter) was used as precursor vessel. The precursor was 
filled to a height of $30 \mathrm{~mm}$. As carrier gas argon with a flow rate of $5 \mathrm{I}_{\mathrm{n}} \mathrm{h}^{-1}$ was used. The evaporation rate was determined at least one hour after the evaporation temperature was constant in order to achieve steady state conditions. In Fig. 2 the product of evaporation rate and total pressure is plotted versus the reciprocal temperature. Since the binary diffusion coefficients are proportional to $\mathrm{p}^{-1}$, the product of evaporation rate and total pressure is independent of pressure. The activation energy for the evaporation of BB'B"-Trichloroborazine was determined to be $65 \pm 2 \mathrm{~kJ} \mathrm{~mol}^{-1}$. This was in good accordance with the value of $71 \mathrm{~kJ} \mathrm{~mol}^{-1}$ reported by Brown et al. [7].

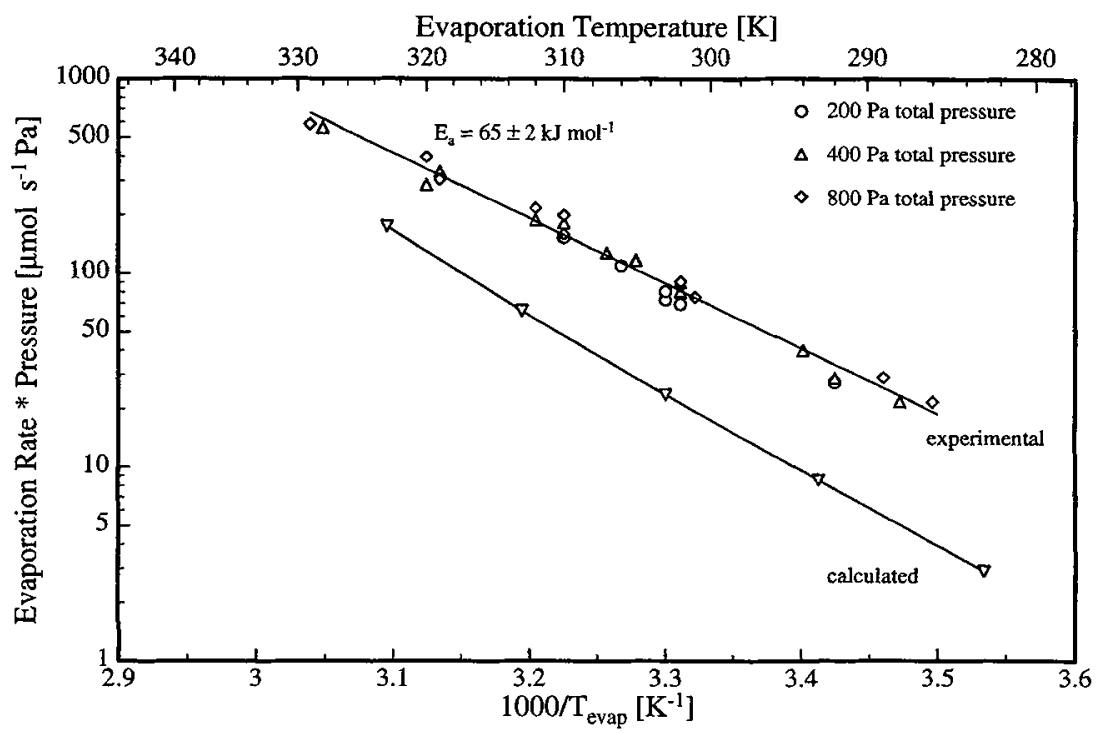

Fig. 2. Product of total pressure and evaporation rate versus the reciprocal evaporation temperature

For comparison the evaporation rate of BB'B"-Trichloroborazine was calculated with the finite difference computer code Fluent (Version 4.25, Creare Inc.). The calculations were carried out for evaporation temperatures of $283,293,303,313$ and $323 \mathrm{~K}$ at pressures of 200,400 and $800 \mathrm{~Pa}$. The vapor pressure $p_{i}$ for $\mathrm{BB}^{\prime} \mathrm{B}^{\prime \prime}$-Trichloroborazine was calculated for every temperature $\mathrm{T}$ according to the equation given by Brown et al. [7] to $p_{i}=4.7 * 10^{13} * \exp \left(-\frac{70600 \mathrm{Jmol}^{-1}}{R^{*} T}\right)$

For the calculation of the diffusion coefficients, the Lennard Jones parameters for BB'B"Trichloroborazine and Argon were needed as input for Fluent. The following values were used:

Ar: $\sigma=3.542 \AA, \varepsilon / \mathrm{k}_{\mathrm{B}}=93.3 \mathrm{~K}$; BB'B"-Trichloroborazine: $\sigma=6.236 \AA, \varepsilon / \mathrm{k}_{\mathrm{B}}=526.7 \mathrm{~K}$

The values for Argon were taken from Reid et al. [8], $\sigma$ for BB'B"-Trichloroborazine was estimated from the LeBas volume $V_{b}$ according to $\sigma=1.18 * V_{b}, \varepsilon / \mathrm{k}_{\mathrm{B}}$ was determined from the boiling temperature at normal pressure $T_{b}$ to $\varepsilon / \mathrm{k}_{\mathrm{B}}=1.15 * T_{b}$ [8]. The boiling temperature $T_{b}$ for BB'B"-Trichloroborazine is $458 \mathrm{~K}$ [9], the LeBas volume was estimated from increment methods given by Reid et al. [8]. Since no increment values for boron were available, the LeBas volume was estimated for Trichlorobenzene that is isoelectronic with BB'B"-Trichloroborazine. The value obtained was $V_{b}=147.6 \mathrm{~cm}^{3} \mathrm{~mol}^{-1}$.

As can be seen from Fig. 2 the calculated product of evaporation rate and total pressure is lower than the experimental values by a factor of approximately 3 and the slope is slightly different. Since the estimation of diffusion coefficients according to the methods described above will not amount to such a deviation, the vapor pressure of BB'B"-Trichloroborazine is assumed to be larger than the values given by Brown et al. [7].

\subsection{Deposition of boron nitride on silicon}

The deposition of $\mathrm{BN}$ from $\mathrm{BB}^{\prime} \mathrm{B}^{\prime}$-Trichloroborazine was investigated on single-crystalline (111)-oriented Si-substrates $\left(40 \times 30 \mathrm{~mm}^{2}\right)$ in the microbalance setup. The investigated range is shown in Table 3 . 
Table 3. Parameter for boron nitride deposition from BB'B"-Trichloroborazine

\begin{tabular}{|l|c|c|c|c|c|}
\hline & I & II & III & IV & V \\
\hline Total pressure $[\mathrm{Pa}]$ & 250 & 500 & 1000 & 1000 & 2000 \\
\hline Gas flow $\left[\mathrm{I}_{\mathrm{n}} \mathrm{h}^{-1}\right]$ & 7.5 & 7.5 & 7.5 & 15 & 15 \\
\hline $\mathrm{T}_{\text {evap }}$ (Low) $/ \mathrm{T}_{\text {evap }}($ High) $[\mathrm{K}]$ & $293 / 333$ & $293 / 333$ & $293 / 333$ & $293 / 343$ & $293 / 343$ \\
\hline
\end{tabular}

To measure the influence of the precursor concentration on the deposition rate, the following procedure was carried out at each deposition temperature: The evaporator was kept at the lower temperature level (indicated as $\mathrm{T}_{\text {evap }}$ (Low) in Table 3 ) until the deposition temperature was reached. During this time the evaporated precursor was passed through the bypass line into the cooling trap. After the deposition temperature was constant for 20 minutes, the bypass valve was closed and the valve for the reactor line opened. The evaporator temperature was raised to its upper level (indicated as $T_{\text {evap }}$ (High) in Table 3). The evaporation rate increased continuously until a maximum value was reached after approximately 45 minutes. The deposition rate was recorded as a function of the precursor concentration (upward branch). Then the evaporator temperature was set to its lower level, so that the evaporation rate decreased while the evaporator cooled down. The deposition rate was recorded again as a function of the precursor concentration (downward branch). After 45 minutes the reactor line valve was closed and the bypass line opened. Subsequently the next deposition temperature was selected and the cycle started again. The deposition temperature was increased from $1053 \mathrm{~K}$ to $1233 \mathrm{~K}$ in steps of $20 \mathrm{~K}$. The advantage of this procedure was, that changes of the surface caused by the deposition process could be monitored. As can be seen in Fig. 4 the deposition rate is not influenced by the deposition process up to temperatures of 1193 $\mathrm{K}$. At higher temperatures the deposition rate of the downward branch is slightly larger than the one of the upward branch, which can be explained by a rougher surface, caused by particle formation.

\subsubsection{Influence of gas flow}

In Fig. 3 the deposition rate at $1193 \mathrm{~K}$ is shown as a function of the precursor concentration at the reactor inlet for different deposition conditions. Two effects are obvious:

- The deposition rate is not proportional to the precursor concentration. This suggests, that saturation effects on the substrate surface occur.

- The deposition rate increases with increasing gas velocity. The dependence of the deposition rate on the precursor concentration is alike, if the gas velocity $w$ and therefore the residence time $\tau=x / w$ of the precursor in the hot zone of the reactor are the same (see curves II/IV and II/V, $x$ : distance from the inlet to the center of the substrate). This leads us to the conclusion, that gas phase reactions occur.

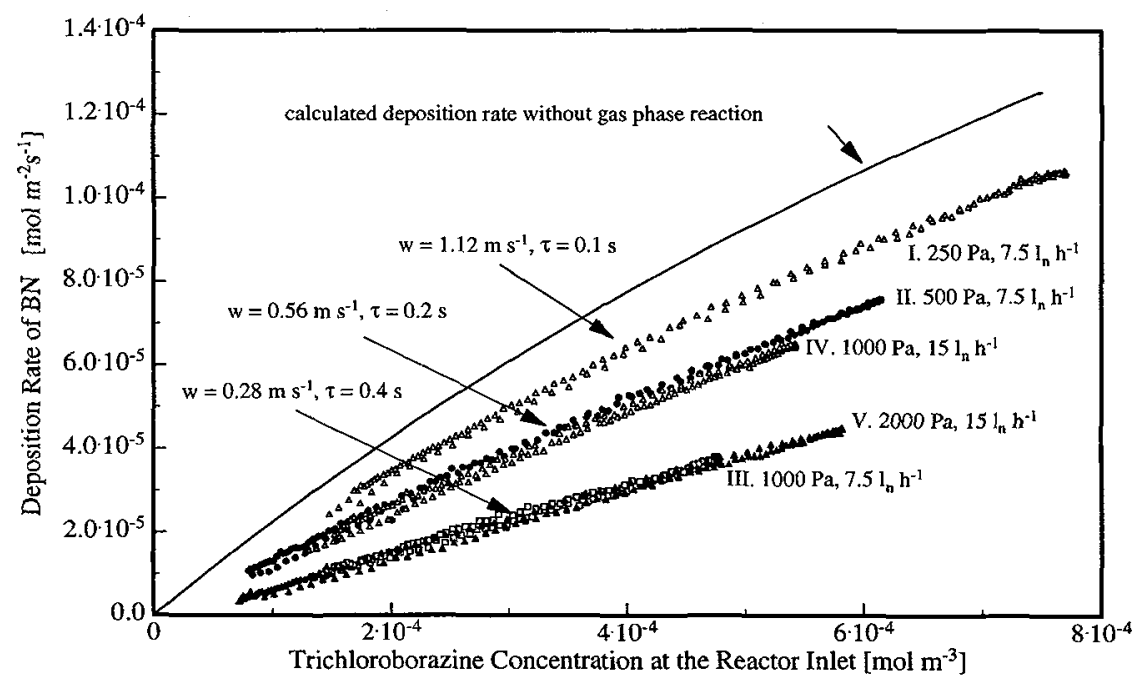

Fig. 3. BN-deposition rate at $1193 \mathrm{~K}$ on $\mathrm{Si}$ at various flow conditions 
For a steady-state plug flow reactor with a first order gas phase reaction the concentration of the reacting species $i$ along the reactor axis is described by equation (1).

$c_{i(x)}:$ concentration at the distance $\mathrm{x}$ from the reactor inlet $\left[\mathrm{mol} \mathrm{m}^{-3}\right]$

$c_{i(x)}=c_{i(x=0)} * \exp \left(-\frac{k^{*} x}{w}\right)$

$c_{i}(x=0):$ concentration at the reactor inlet $\left[\mathrm{mol} \mathrm{m}^{-3}\right]$

$k$ : reaction constant for the gas phase reaction $\left[\mathrm{s}^{-1}\right]$

$x$ : distance from the reactor inlet $[\mathrm{m}]$

$w$ : gas velocity in the reactor $\left[\mathrm{m} \mathrm{s}^{-1}\right]$

For the experimental setup the concentration $c^{\prime}$ at the center of the substrate is given by $c^{\prime}=c_{(x=0)}{ }^{*} \exp \left(-\frac{k^{*} 0.115[m]}{w}\right)$. Values for the constant $k$ are given in section 3.4.2.

\subsubsection{Influence of temperature and precursor concentration}

In Fig. 4 the $\mathrm{BN}$ deposition rate is shown for different temperatures as a function of the precursor concentration at the reactor inlet.

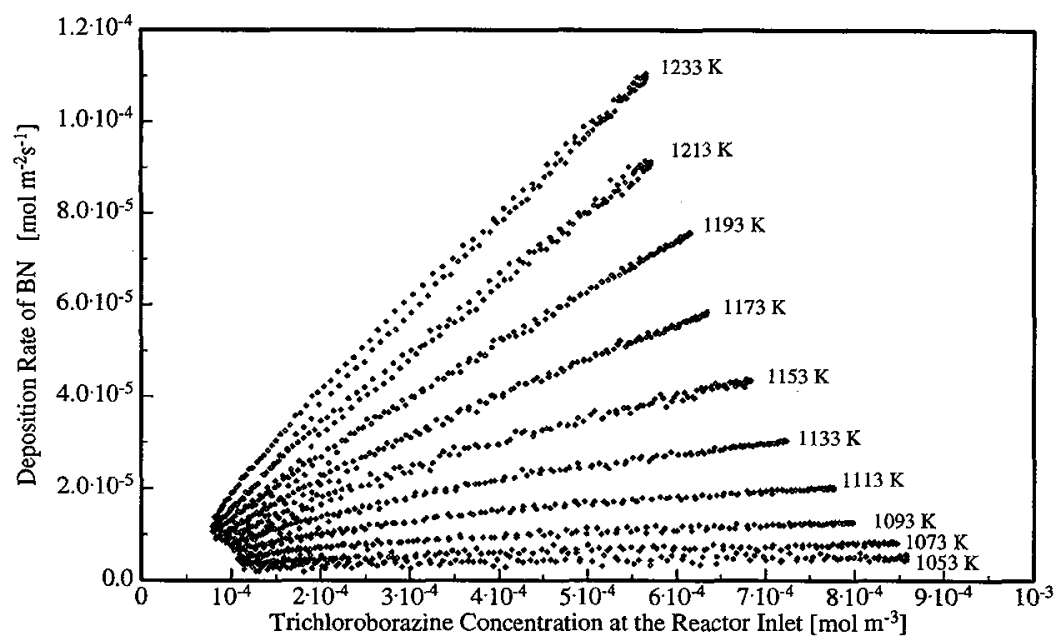

Fig. 4. BN-deposition rate on $\mathrm{Si}$ as a function of precursor concentration at the reactor inlet at different temperatures. $\left(p_{\text {tot }}=1000 \mathrm{~Pa}\right.$, Flow $\left.=15 \mathrm{In} \mathrm{h}^{-1}\right)$

The deposition rate can be described as a Langmuir reaction according to equation (2).

$$
\begin{aligned}
& r=\frac{k_{r} * K_{C} * c^{\prime}}{1+K_{C} * c^{\prime}} \\
& r \text { : deposition rate }\left[\mathrm{mol} \mathrm{m}^{-2} \mathrm{~s}^{-1}\right] \\
& k_{r} \text { : reaction constant of deposition reaction }\left[\mathrm{mol} \mathrm{m} \mathrm{m}^{-2} \mathrm{~s}^{-1}\right] \\
& K_{c} \text { : Equilibrium constant of Trichloroborazine adsorption on } \mathrm{BN}\left[\mathrm{m}^{3} \mathrm{~mol}^{-1}\right] \\
& c^{\prime} \text { : precursor concentration at the substrate according to equation (1) }\left[\mathrm{mol} \mathrm{m}^{-3}\right]
\end{aligned}
$$

In Fig. 5 the constants $k_{r}, K_{c}$ and the constant $k$ for the homogeneous gas phase reaction given by equation (1), are plotted versus the reciprocal temperature. The values were determined from the experiments by numerical fit. The following expressions for the constants and their pre-exponential factors $k_{r_{0}}, K_{C_{0}}$ and $k_{o}$ were obtained:

$$
\begin{array}{rlr}
k_{r}=7.9 * 10^{9} * \exp \left(-\frac{303000 \pm 16000 \mathrm{Jmol}^{-1}}{R^{*} T}\right) & {\left[\mathrm{molm}^{-2} \mathrm{~s}^{-1}\right]} & k_{r_{0}}=7.9 * 10^{9} \mathrm{molm}^{-2} \mathrm{~s}^{-1} \\
K_{C}=1.66 * 10^{-5} * \exp \left(\frac{172000 \pm 15000 \mathrm{Jmol}^{-1}}{R^{*} T}\right) & {\left[\mathrm{m}^{3} \mathrm{~mol}^{-1}\right]} & K_{C_{0}}=1.66 * 10^{-5} \mathrm{~m}^{3} \mathrm{~mol}^{-1} \\
k=18250 * \exp \left(-\frac{89000 \pm 10000 \mathrm{Jmol}^{-1}}{R^{*} T}\right) & {\left[\mathrm{s}^{-1}\right]} & k_{0}=18250 \mathrm{~s}^{-1}
\end{array}
$$




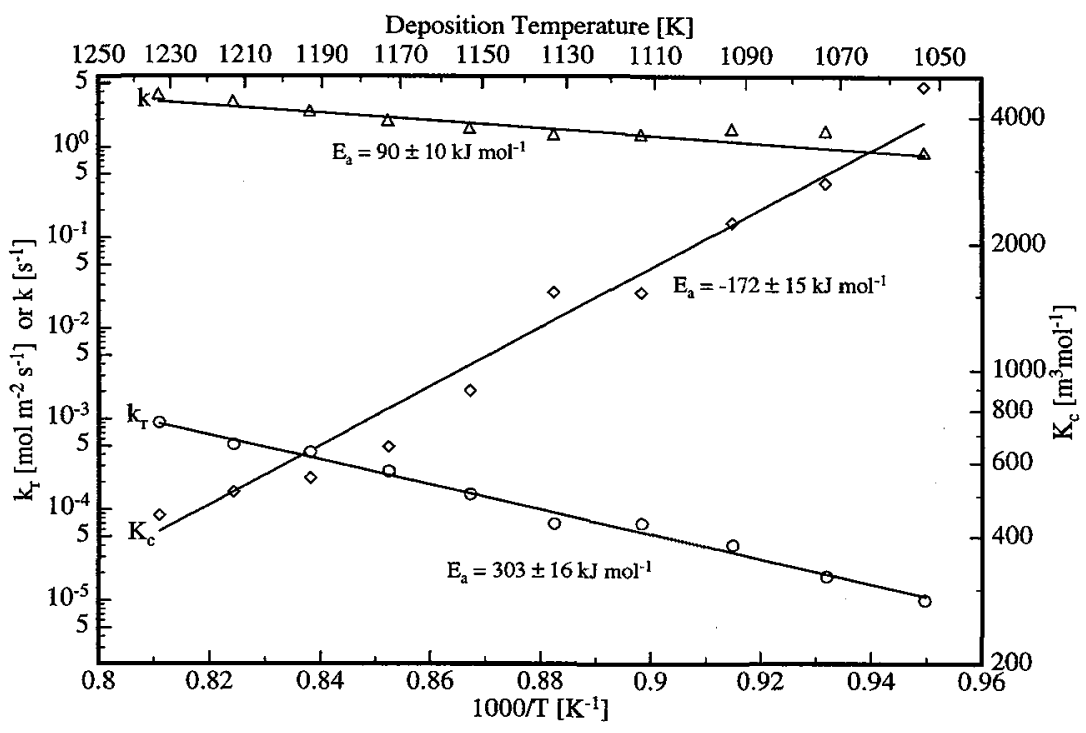

Fig. 5. $\mathrm{K}_{\mathrm{c}}, \mathrm{k}_{\mathrm{r}}$ and $\mathrm{k}$ versus the reciprocal temperature

\subsubsection{Calculation of $k_{r_{0}}, K_{C_{0}}$ and $k_{0}$ by statistical mechanics}

According to the activated complex theory formulated by Eyring, the pre-exponential factors for the constants $\mathrm{k}_{\mathrm{r}}, \mathrm{K}_{\mathrm{c}}$ and $\mathrm{k}$ can be estimated by their partition functions multiplied with $k_{B} T / h$ with $k_{B}$ : Boltzmann constant, $h$ : Planck constant and $T$ : absolute temperature [10,11]. If one assumes that the precursor molecule is adsorbed on equivalent sites with a density of $10^{19} \mathrm{~m}^{-2}$ and takes into account only the translation partition functions in the gas phase, the following pre-exponential factors are obtained:

$$
\begin{aligned}
k_{r_{0}} & =3 * 10^{12} \mathrm{molm}^{-2} \mathrm{~s}^{-1} \\
K_{C_{a}} & =6 * 10^{-9} \mathrm{~m}^{3} \mathrm{~mol}^{-1}
\end{aligned}
$$

These values compare quite well with the measured values if one considers the omission of rotational and vibrational sums. The pre-exponential factor of the homogeneous reaction should be in the range of $k_{B} T / h$ which would give a value of approximately $10^{13} \mathrm{~s}^{-1}$. The experimental value of $k_{0}=1.82 * 10^{4} \mathrm{~s}^{-1}$ shows, that probably a more complicated decomposition mechanism occurs.

\subsection{Analysis of the deposited layers}

The layers were investigated by SEM, XRD and IR-Transmission spectroscopy. The layers were smooth and amorphous. The chlorine content, determined by WDX-analysis was less than one atomic percent. The density of the deposited layers was calculated from SEM-fracture-photos and mass gain to $1.4 \mathrm{~g} \mathrm{~cm}^{-3}$ as it was reported for pyrolytic BN by Moore et al. [3]. The infrared spectra showed peaks at $v=1380 \mathrm{~cm}^{-1}$ and $v=790 \mathrm{~cm}^{-1}$.

\subsection{Deposition on Tyranno-fibers}

Based on the results obtained in the microbalance measurements, Tyranno-fiber fabrics of $150 \times 30 \mathrm{~mm}^{2}$ were coated with boron nitride from BB'B"-Trichloroborazine in a horizontal hot wall CVD reactor with $85 \mathrm{~mm}$ diameter. The pressure was varied from 250 to $1000 \mathrm{~Pa}$ and the deposition temperatures were in the range between 973 and $1173 \mathrm{~K}$ at a total gas flow of $7.5 \mathrm{I}_{\mathrm{n}} \mathrm{h}^{-1}$. Uniform coatings of approximately $300 \mathrm{~nm}$ thickness were obtained at temperatures below $1073 \mathrm{~K}$. The uniformity of the coating increased with decreasing total pressure. A SEM picture of coated fibers is shown in Fig. 6. In comparison to the uncoated fibers a tensile strength decrease of approximately $15 \%$ was observed for the coated fibers. Oxidation tests in $\mathrm{Ar} / \mathrm{O}_{2}$ with an oxygen partial pressure of $20000 \mathrm{~Pa}$ showed, that oxidation started at temperatures above $873 \mathrm{~K}$ leading to a brittle behavior of the fibers. 


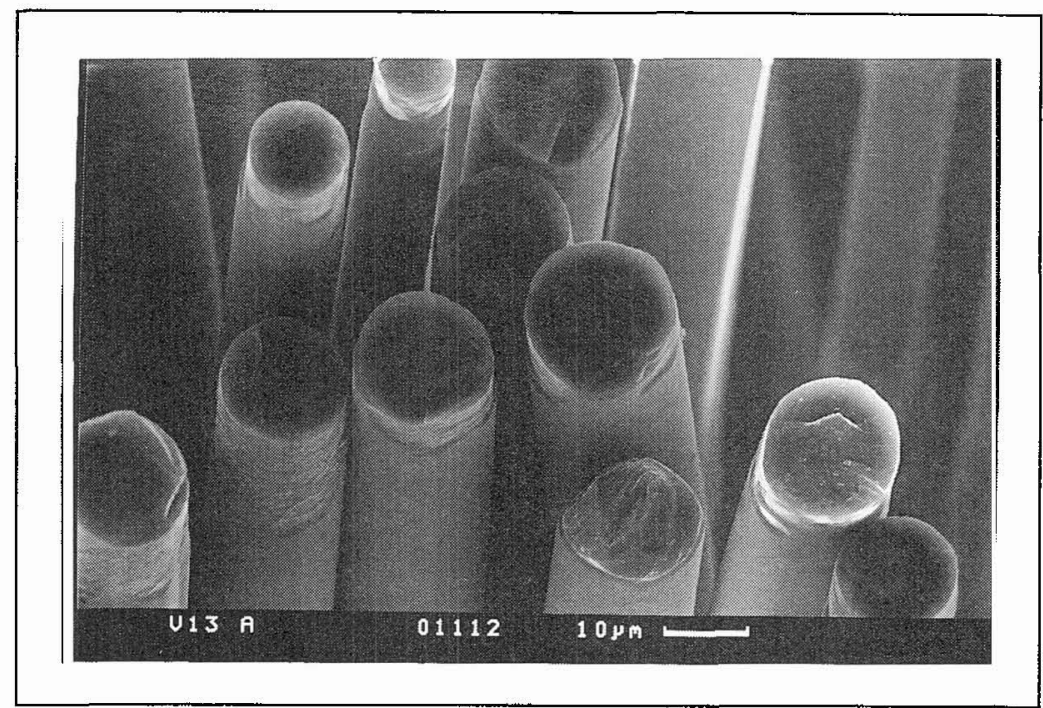

Fig. 6. SEM-Picture of BN-coated Tyranno-fibers $\left(T_{\text {dep }}=1023 \mathrm{~K}, p_{\text {tot }}=500 \mathrm{~Pa}\right)$

\section{CONCLUSIONS}

Stoichiometric boron nitride layers were deposited from BB'B"-Trichloroborazine. The precursor was easy to prepare and was used to coat Tyranno-fibers fabrics with high uniformity at temperatures between 973 and $1073 \mathrm{~K}$. The deposited layers were amorphous and began to oxidize under atmospheric conditions at temperatures above $873 \mathrm{~K}$. For that reason their application as an interlayer in CMC's is restricted to temperatures below this value unless protection against oxygen attack is achieved in a different way.

\section{ACKNOWLEDGEMENTS}

The authors want to thank the German Ministry for Research and Technology (BMFT) and MAN Technology AG, Munich, for their support of this work. The mechanical properties of the fibers were tested by MAN.

\section{REFERENCES}

[1] H. Hannache, R. Naslain, Journal of the Less-Common Metals, 95 (1983), 221-246

[2] A.W. Moore, Mat. Res. Soc. Symp. Proc., 250 (1992), 269-274

[3] D.J. Pysher, K.C. Goretta, R.S. Hodder, R.E. Tressler, J. Amer. Ceram. Soc. 72 (1989), 284-88

[4] H.W. Lösch, J.V. v. Vietinghoff, W. Wagner, R. Kleinrahm, "Magnetic suspension balances for research and industry", $25^{\text {th }}$ Conference on Vacuum Microbalance Techniques, Siegen, Germany, 2-4 Sept. 1993, J. Keller, E. Robens (Eds.), (Multi-Science Publishing Co. Ltd, Brentword, Essex, U.K. 1994)

[5] J.J. Gebhardt, "CVD Boron Nitride Infiltration of Fibrous Structures: Properties of Low Temperature Deposits", $4^{\text {th }}$ Int. Conf. on Chemical Vapor Deposition, Boston, 8-11 Oct. 1973, G.F. Wakefield, J. M. Blocher (Eds), (Electrochemical Society, Princeton NJ, 1973), pp 460-472

[6] R.N. Singh, "LPCVD of Boron Nitride from Beta-Trichloroborazine", 10 Vapor Deposition, Honolulu, Oct. 1987, G.W. Cullen, J. M. Blocher (Eds), (Electrochemical Society, Princeton NJ, 1987), pp 543-551

[7] C.A. Brown, A.W. Laubengayer, J. Am. Chem. Soc., 77, (1955), 3699-3700

[8] Reid R.C., Prausnitz J.M., Poling B.E., "The properties of gases \& liquids", Fourth Edition, McGraw-Hill Book Co., New York 1987

[9] A.W. Laubengayer, C.W.J. Scaife, J. Chem. Eng. Dat., 11, (1966), 172-174

[10] Hill, T.L., "Statistical Mechanics", Dover Publications Inc., New York 1987

[11] Atkins, P.W., "Physical Chemistry", Third Edition, Oxford University Press, Oxford 1986 